\title{
A TRIZ Approach to Pressure Cooker Lid Opening Innovative Design
}

\author{
XinZhang \\ Guangdong University of Technology, Guangzhou 510000, China
}

\begin{abstract}
Keywords:TRIZ, innovative design, pressure cooker, lid, theory of inventive problem solving.
\end{abstract}
\begin{abstract}
We are always good at analyzing individual problems and finding their solutions using TRIZ tools. In practice, however, innovative professionals tend to be confronted with multiple problems rather than one. In this study, innovative tools such as "analogy", "ideal final result" (IFR), "resource analysis" and "physical contradictions" are proposed as solutions to a series of problems. It is nothing but a better understanding of TRIZ tools that can turn TRIZ to better use in solving complex system problems.
\end{abstract}

\section{Basic TRIZ Tools and Procedures of Solving Complex System Problems}

TRIZ is a Russian acronym of "the theory of inventive problem solving". It is a theory born in line with the objective law of technical system development, and also a theory on innovative method which can finally bring to technical management innovations. Generally, "Classical TRIZ” is used to refer to the theory originally developed by G. S. Altshuller and his associates between 1946 and $1986^{[1]}$. The new development of this theory after 1986 by the students of Altshuller is called "Modern TRIZ". The latter is a significant enrichment of the former, mainly in terms of problem analysis method and specialized application. In academia, it is generally recognized to have three major elements ${ }^{[2]}: 1$ ) its methods of analysis include functional analysis, causality analysis, resource analysis and process analysis; 2) its branch theories include SIT, ASIT, USIT, WOIST, I-TRIZ and OTSM-TRIZ; 3) its computer-aided innovation software includes GoldFire, IWB and Pro/Innovator.

The excellence of a theory is determined by the extent to which it can guide practices. As a practically helpful theory in solving innovation problems, TRIZ has more emphasis on the combined results of production and research practices ${ }^{[3]}$. We tend to be very good at solving individual problems using TRIZ tools, but in practice innovative professionals always come across a series of problems rather than one. In such cases, it is important to make use of TRIZ and positive thinking tools such as "analogy" and "ideal final result" (IFR). This will facilitate better use of TRIZ and cultivation of the habit of using these tools.

Procedures of a TRIZ approach to complex system problems solving [4]:

1) Identifying negative effects. What are the things undesirable in the case?

2) Asking question: How to eliminate the negative effect?

3) Inventing tools and solving problems by means of "analogy": seeking problem-solving strategy, seeking resources that can realize the strategy, obtaining solutions, and assessing solutions by evaluating standards. If a solution is found, the analysis comes to an end; if otherwise, it is time to turn to the next tool, the IFR. Inventing tools and solving problems by means of IFR: seeking problem-solving strategy, seeking resources that can realize the strategy, obtaining solutions, and assessing solutions by evaluating standards. If no solution is found or the needed resources are unavailable, it is time to seek the right "energy resource".

4) If there is still no satisfactory solutions, it is time to find the "technical contradictions", then solve these contradictions by resorting to "standard solution", and then reveal and solve "physical contradictions”. In this manner, TRIZ tools are kept in use until solutions are found.

\section{Organization of the Text}

The TRIZ approach to innovative design will be demonstrated in detail by the issue of "pressure cooker lid opening”. 


\subsection{Working Principle and Parameters of the System.}

The vast majority of pressure cookers work on the principle that air pressure is directly correlated to the boiling point of water ${ }^{[5]}$. In simple words, water in the pressure cooker will evaporate if heated. If kept heated, the vapor will produce increasingly greater pressure, and the boiling point of water will be raised accordingly. In that way, the temperature inside the cooker will exceed $100{ }^{\circ} \mathrm{C}$. Such high temperatures can be used for cooking or sterilizing.

Safety devices in a pressure cooker: First, the safety valve. When the inner pressure of the cooker exceeds a certain limit, the safety valve will be jacked up, keeping its inner pressure below that limit; Second, and easy-to-melt plate made of low-melting-point alloys. In case of safety valve failure, the plate will be melted when the temperature inside the cooker reaches its melting point, and the vapor will be let out from the plate. It helps to prevent explosions. Ordinary pressure cookers work in this way: first, the heated water evaporates and rises up; second, the vapor jacks up the safety valve; then, the safety valve seals the cooker; finally, food is ready and the safety valve vents.

The research subject in this study is ordinary pressure cookers which can be heated by gas stove or induction cooker, rather than electric pressure cookers. In the case of aluminum alloy pressure cooker with stainless steel bottom, big open flame should be avoided so as to prevent rapid cooling and deformation-induced falling out of its bottom.

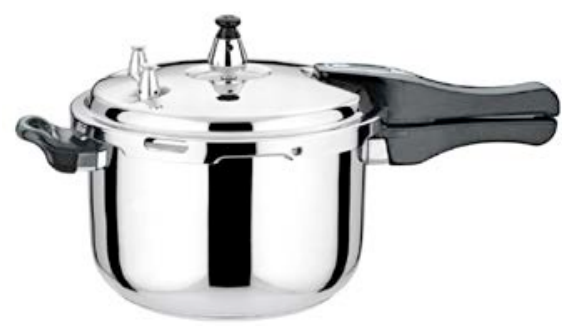

Fig. 1 Ordinary Pressure Cooker

(1)

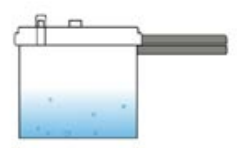

(2)

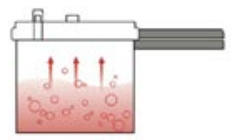

(3)

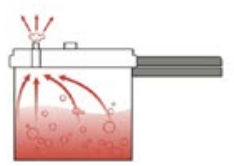

Fig. 2 Ordinary Pressure Cooker Working System

\subsection{Problems in Current System.}

1) Currently available ordinary pressure cooker always has a long handle. To open and close the lid, both hands have to be used. The long handle will be a big problem particularly if its user has a crowded kitchen.

2) Opening the lid of an ordinary pressure cooker needs the operation of both hands and much arm strength, which will be a great difficulty for some women.

3) When the lid of an ordinary pressure cooker is closed, the marks on the lid and the cooker body should be rightly aligned to ensure perfect locking. It takes time and efforts. Also, every time before use checking should be done to ensure that the vent of the safety value is unblocked. Blocked safety valve or vent will lead to accidents.

\subsection{IFR of the System.}

It is a common practice in natural sciences to idealize a research subject ${ }^{[6]}$. In others words, an idealized object is in essence the limit state of an existing object in reality. This method is very 
meaningful to some fields of study, for example, lines, planes, and ideal liquids in physics. There is also a powerful idealization TRIZ tool that has promoted the development of innovative design.

Product evolution is by nature a process where a product develops from a low form to a high form $^{[7]}$. At some stage of evolution, different product will evolve in different directions. For example, some products will evolve towards energy saving but some towards increased added values. If all the products are seen as a whole, an ideal product should be highly reliable, cost-effective, etc. The solution to the ideal state of products is called ideal final result (IFR) ${ }^{[4]}$.

The obtaining of idealized solutions is by nature a process of improving idealization performance. The solution with an infinitely high idealization level is the IFR. In order to reach the ideal state of low cost, high efficiency, high reliability, no pollution, etc, multiple ideal results for a product will be reached first. All these ideal results lead up to the IFR.

By needs analysis, it can be determined that the ideal results of a product is a set of:

$\operatorname{IFR}=\left\{\operatorname{IFR}_{1}, \operatorname{IFR}_{2}, \ldots, \operatorname{IFR}_{k}, \ldots, \operatorname{IFR}_{l}\right\}(k \leq l)$

Among which $l$ is the total number of ideal results? The every step of development of a product from its current or initial state to its ideal result requires the achieving of a series of goals, while the achieving of every goal involves obstacles. These obstacles is a set of:

$\mathrm{C}_{K i}=\left\{\mathrm{C}_{\mathrm{k} 1}, \mathrm{C}_{\mathrm{k} 2} \ldots \mathrm{C}_{K L}\right\}$

The relation between IFR and every ideal result can be expressed as:

Ideality $=[C][$ IFR $]$

The IFR consists of a number of IFRs, while the obtaining of every IFR requires the removal of a number of obstacles and achieving of a number of targets. The IFR gets rid of the defects of the original system but maintains its merits; it neither complicates the system (by using no-cost or available resources) nor brings new defects.

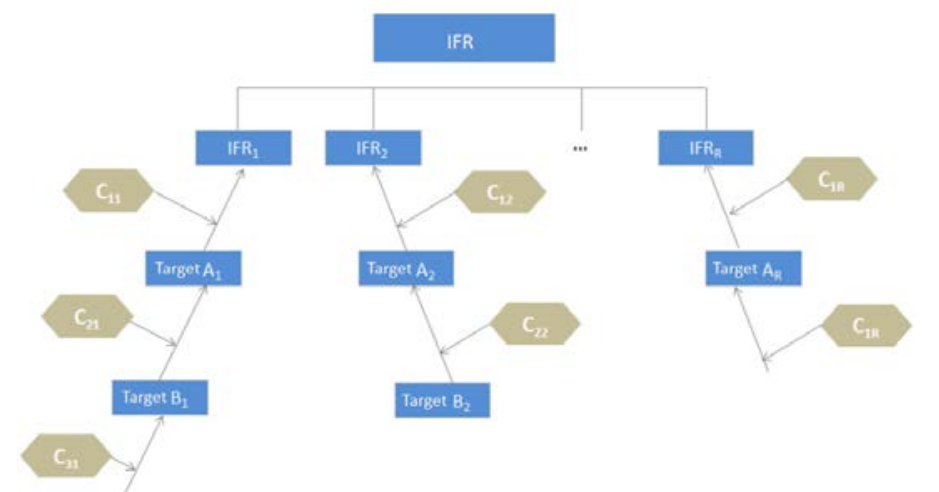

Fig. 3 How an IFR is obtained

As to the issue of pressure cooker lid opening, my proposed IFR is such: the sticking-out handle is not needed; user of the cooker can open and close the lid single handed with ease; the lid is easy to clean and the vent and safety valve never get blocked. How can we achieve this IFR without introducing new materials, or how to make change within the system to solve the problem? Whenever using IFR to solve system problems, we should clarify our target. This is important for any design and innovative work.

\subsection{Problems and Obstacles to be removed before Obtaining System IFR.}

1) Ordinary pressure cookers available now often have a long handle. The upper and lower handles should be used together when the lid is to be opened or closed. However, if the user has a small kitchen, the long handle will be a great disturbance while cooking. Moreover, as the operation of an ordinary pressure cooker requires both hands and much arm strength, it is a great difficulty for some women. How can we get rid of the long handle and make single- hand operation possible? To answer this question, we can use the method of analogy and see in what situations in life we operate with single hand.

By analogy ${ }^{[8]}$ we can find that the knob-way solution is easy to do with single hand and relatively labor saving. Also, it makes the overall size of the cooker smaller. Therefore, for ordinary pressure cookers, the knob way of lid opening is our best solution. 
2) The available lid system in ordinary pressure cookers is not easy to be taken down for cleaning, and its vent should be turned always to prevent food blocking. In some cases, a product has a number of safety valves or multiple safety devices as guarantee.

To solve this problem, I decided to find a better way of lid opening. Now there are two ways of lid opening for pressure cooker systems, i.e., inside lock and outside lock. I selected the inside way, because outside lock is made partly of plastic, which is prone to aging under high temperatures. Outside lock makes the lid hard to clean, and besides, such a design looks not so beautiful. The inside lock solution is good for cleaning, and no complicated surface is needed. All that is needed is metal. Nevertheless, if a pressure cooker with an inside lid lock is to be made perfectly air-tight, the rubber ring has to be pressed tightly against cooker body. This makes lid opening very difficult.

Table 1 Ways of Opening and Closing--An Analogy

\begin{tabular}{|c|c|c|c|}
\hline & Advantage & Disadvantages & Assessment \\
\hline Button & $\begin{array}{l}\text { Single-hand and } \\
\text { easy operation }\end{array}$ & $\begin{array}{l}\text { Pressing button needs much strength, } \\
\text { which is transformed to mechanical } \\
\text { power for lid opening; operation needs } \\
\text { accuracy; not easy to clean }\end{array}$ & $x$ \\
\hline Rotation Handle & $\begin{array}{l}\text { Easy operation } \\
\text { and labor saving }\end{array}$ & $\begin{array}{l}\text { Cooker body should be fixed when } \\
\text { rotating handle to open lid }\end{array}$ & $x$ \\
\hline Slide & $\begin{array}{l}\text { Single-hand, easy } \\
\text { operation, labor } \\
\text { saving }\end{array}$ & $\begin{array}{l}\text { Accurate construction; hard to realize; } \\
\text { not easy to clean }\end{array}$ & $x$ \\
\hline Knob & $\begin{array}{l}\text { Single-hand, easy } \\
\text { operation, labor } \\
\text { saving }\end{array}$ & No & $\sqrt{ }$ \\
\hline
\end{tabular}

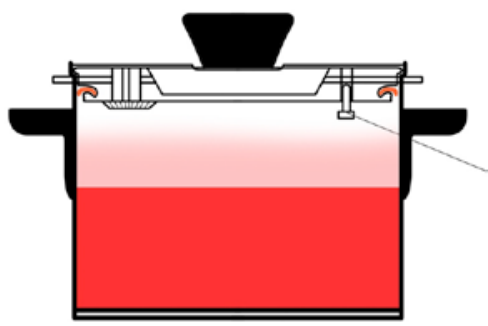

Figure 4 Pressure Cooker with Inside Lock

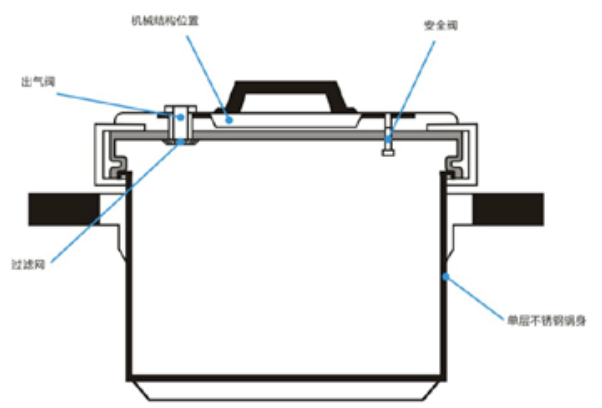

Figure 5 Pressure Cooker with Outside Lock 
On the User's Manual of ordinary pressure cookers, there is always a notice reminding users that they should make sure the pressure limiting valve and the vent are unobstructed every time they use the cooker. Accident will happen if both the safety valve and the vent are blocked. But how to guarantee safety? Some pressure cookers have a number of safety valves, and some have several safety devices, and some feature automatic warnings telling people to check the vent on a regular basis. Now let us think about the IFR in this case: no need to turn the valve or vent; food blocking can be prevented even there is no turning at all. The method of resource analysis can be employed to solve this problem ${ }^{[9]}$.

Resources in the system include: Material resource: upper lid, lower lid, handle, cooker body, cooker handle, food, air; Field resource: heat, vapor, force of opening the lid, liquid surface tension; Time resource: lid closing, pressure increase before and after water boiling, venting; Space resource: cooker chest, space inside the lid 。

By analysis, I decided to select from them field resources ${ }^{[10]}$--using the force of opening the lid to rotate the vent, and installing a filter below the safety valve. Every time users want to open the lid, they have to turn the handle from side to side. If so, it is necessary to design a gear that can amplify a tiny turning force and transform it into side-to-side force to open the lock. The force to turn the cooker handle while opening and closing the lid can also be used to turn the vent, so that the vent always stays clear.

Likewise, the method of resource analysis can also be used to solve another problem, i.e., difficult lid opening for inside-lock pressure cooker where its rubber ring has to be tightly pressed against its cooker body. There is a physical contradiction in this case, namely the need of air-tight locking and no need of air-tight locking between the rubber ring and the cooker body. The time separation principle in TRIZ theory can be applied to this problem. In other words, the rubber ring and the cooker body should not be air-tight locked when the lid is opened, while they should be so when food is being cooked. I kept doing resource analysis to solve this problem. The resources in this system have been enumerated earlier and will not be detailed here. By analysis, I decided to try vapor pressure under the category of field resources to find a solution.

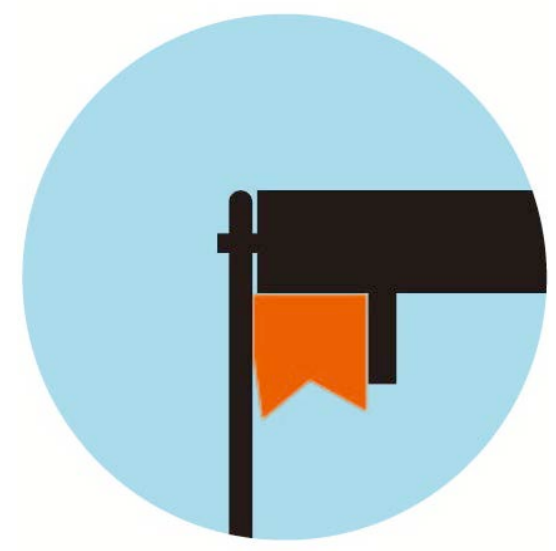

Fig. 7 Rubber Ring at Lid Opening and Closing

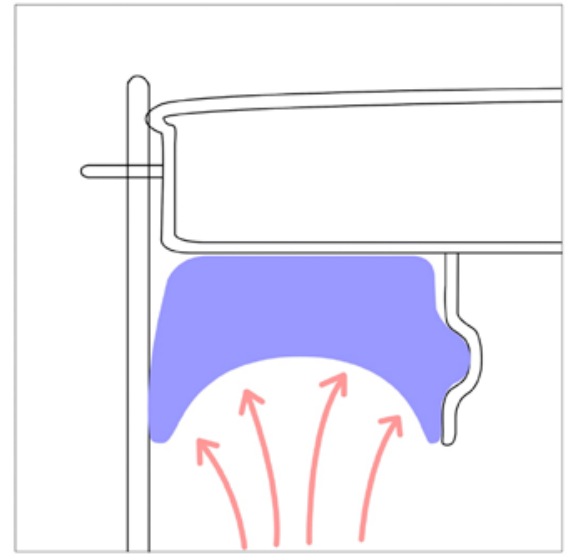

Fig. 8 Rubber Ring while Cooking 
At this point, the IFR of the lid opening system for ordinary pressure cookers has been found. These ordinary pressure cookers have an inside lock, making it easy to operate with single hand; the design makes lid cleaning easy. When the lid is opened or closed, the safety valve and the vent are turned at the same time, which ensures that they never get blocked. Moreover, there is no new material introduced, and the solution is merely a result of changes inside the system.

\section{Summary}

A smart use of TRIZ tools and positive thinking are essential to solve system problems in innovative designing. The case in this study involves the use of TRIZ tools such as "analogy", "ideal final result", "resource analysis", and "physical contradiction". It is nothing but a better understanding of TRIZ tools that can turn TRIZ to better use in solving complex system problems in design.

\section{Acknowledgement}

Foundation Item: Guangzhou Science and Technology Project (No. 2013Y2-00103); Guangdong Provincial Training Project for Excellent Creative Young Teachers in Colleges and Universities (No. 12ZK0092)

\section{References}

[1]. Altshuller. The Innovation Algorithm: TRIZ, Systematic Innovation and Technical Creativity. Trans. by Tan Peibo et al. Huazhong University of Science and Technology Press, 2008.

[2]. BUSOV B, MANND L, JIRMAN P. TRIZ and invention machine: Methods and systems for creative engineering and education in the 21st century[C/CD]// 1st International Conference on Advanced Engineering Design, 1999, May, Prahue, 1999.

[3]. W Beiz, G Pahl. Engineering design: a systematic approach[M], 3rd ed. Spinger, 2007.

[4]. Runhua Tan. TRIZ and Applications: The Process and Methods of Technological Innovation[M]. Beijing: Higher Education Press, 2110.

[5]. Zhou Ke-ping, Li Jie-lin, Lei Tao et al. Innovation design of mining method based on TRIZ methodology[J]. Journal of Engineering Design, 2010, 6(17): 401-405

[6]. Gao Chang-qing. TRIZ--Theory of Innovative Problem Solving[M]. Beijing: Science Press, 2011. 56-72

[7]. MIKE HOBDAY, HOWARD RUSH, JOE TIDD. Innovation in complex products and systems[J]. Research Policy, 2000(29), 793-804.

[8]. KaleviRantanen and Ellen Domb. Trans. Tan Run-hua et al. Simplified TRIZ: New Problem Solving Applications for Engineers and Manufacturing Professionals [M]. Beijing: China Machine Press, 2010.

[9]. H.K.TANG. An integrative model of innovation in organizations[J]. Technovation, 1998(5): 297-309.

[10]. DR. ROBERT COOPER. Winning at new products: path- ways to profitable innovation, enterprise project management solution[M]. New York: Basic Books, 2006.

[11]. THEODORE J. KRENZE R. Multi-axis bevel and hypoid gear generating machine:USA, 4981402[P] 1987-08-24

[12]. Suh N P. Axiomatic design: advances and applications[M].MIT Press, 2000 